\title{
The Creation and Usage of Media in the Science Courseware
}

\author{
Hongying Zhang \\ Department of Educational Technology, Jiangnan University, Wuxi, China \\ Email: zhanghy2002@vip.sina.com
}

Received January 2014

\begin{abstract}
In the process of creating science courseware for the new curriculum Science in China, a variety of media should be created and properly used. In this paper, the principles of media creation and application are discussed. The media creation should follow five points: scientific, effective, inspirational, technological, and artistic. The media application has to be consistent with using aims, teaching content, teaching ways, and student cognition structure. At last, some media examples are illustrated.
\end{abstract}

Keywords

Scicence Courseware, Media Creation, Media Application

\section{Introduction}

The curriculum Science has its new standard in China, which emphasizes much more information resource. Developing multimedia courseware is an important part of curriculum resource [1].

As a main member, the author made the courseware of Science of grade 7 (version of Eastchina Normal University Press) [2]. In the process of making its courseware, much more media materials are needed. Media materials are the basic elements for communicating teaching information. When we create and use media in Science courseware, there are some principles we should follow.

\section{The Principles of Creating Media}

\subsection{Scientific}

No matter what kinds of media, it must be actual and scientific. Science seek truth itself and against falsification. Without actual there would be no science. In order to show the knowledge correctly, the media should be selected and created scientifically.

\subsection{Effective}

One important way to improve teaching quality is optimization of teaching process. It is necessary to give the most representative media for the same kind of appearance and law. Representative media will effectively reach 
teaching aims. These effective media would make the essence clear and make teaching process efficient.

\subsection{Inspirational}

For students, the content of media should inspire their learning enthusiasm. With inspirational media, students may have great advances on thinking, analyzing, and imaging of problems.

\subsection{Technological}

For the media in Science courseware, there are some technical requirements on sharpness, size, page structure and so on. For example, the video media should have clear page, steady picture, good sharpness, real color. Three kinds of sound, narration, effect sound, and background, must have appropriate proportion in the volume.

\subsection{Artistic}

Any kinds of teaching contents ought to show artistic and so do media. The design of media should accord with the aesthetics principles. The content and form of media should make students to have a nice feeling and then bring the enthusiasm into learning.

\section{The Principles of Using Media}

\subsection{Consistent with the Using Aims}

Each knowledge unit in the Science courseware has its own teaching aims. We need different media to deliver the teaching information, which is the using aim of media. If the media fit the using aim, the teaching aim would be reached effectively. For example, one teaching aim is to make students understand one kind of theory, we can use media in giving the whole process of motion, grow and develop of one typical thing. Combined with the description of text, the media application would help students know the law very well.

\subsection{Adapt to the Teaching Contents}

Different course need different media and different units in one course need different media too. To the Science course, this characteristic is especially obvious because it includes different courses such as physics, chemistry, biology, geography, astronomy and so on. We must consider demands of each course when using media in courseware. For example, sometimes, the teaching content is the factual things in the science developing history, we can make students get actual feeling and remember the content easily by using media show the correlative materials lively.

\subsection{Cohere with Teaching Ways}

The core of Science course is science inquiry, so the teaching way is turning to student-centered. Discovery method and inquiry method are becoming more and more important. The media would be good for establishing the situation for discovery and inquiry, bringing along the students' learning initiative, promoting students to discover problems and solve them constantly, enhancing students' knowledge and capability at last.

\subsection{Appropriate for Students' Cognition Structure}

Cognition structure is the content and form about the concepts of some knowledge fields and it is considered as one of self factors which make important impact on learning. Students often learn new knowledge by using old cognition structure and form new cognition structure [3]. So, the media we used in courseware should be a bridge which can guide students from old knowledge to new knowledge.

\section{The Concrete Application of Media in Science Courseware}

\subsection{Text Media}

We used text media as some short hints and simple introduction not large length. For example, we use text 
putting some inquiry questions after showing some videos such as "What did you see?" "What did you think about?" “Can you put forward some resolving ways?” and so on. When showing some contexts needs a process, we can lead students continue learning by shinning the hint text in the process.

\subsection{Graphic Media}

Graphic media are used in science courseware as two goals such as directory guide and show content.

When graphics are used as directory guide, we can make diversify the guide way and reduce optical and thinking insipid arose by only text directory. For example, there are two subjects in section 1 of Chapter 1: the secrets of the nature and wonderful experiment phenomena. There are several small topics which provide free selection to students. We use text buttons to guide the two subjects and using graphic to guide the small topics. Each graphic embodies the content of each topic such as the soap bubble graphic means a series soap bubble experiments, the penguin graphic means the exploration about penguin and the South Pole.

On the other hand, we use graphics as show content because we want to enlarge the schoolbook content. Some rare pictures such as the STM of silicon crystal surface are used in courseware. We provide pictures when some contents are just described by text in the schoolbook. For instance, in the topic of the types and application of soil, we used many pictures of concrete examples in order to help students understand the schoolbook profoundly.

\subsection{Animation Media}

Animation media is more lively than graphic, but it is not so good that use lots of animation media. In science courseware, we used animation media in four aspects such as express the micro-world, make the content more lively, express the content which can't shoot fully, express the experiments which hardly reappear. For example, the process of the form of soil is very long, it is impossible to record a video, we use animation to express this process clearly and simply. Another example, scientists made two experiments to explore the bat flying depend on eyes or ears. There are only word expression and no any video, we used animation to reappear the experiments and make the topic interesting.

\subsection{Video Media}

Video is the most strongly media of expressive force and infective force. There are lots of video media in science courseware mainly used in three aspects.

One is to show the phenomenon can't be seen usually such as the flycatcher in biology.

Next is the experiments that hardly success once in classroom or the experiments that need long time and there is not enough time to finish in classroom.

Last is the experiments that there are no equipments in school to do or the experiment is danger to students such as the experiments of liquid nitrogen.

When we make video media, we should pay attention to four points that the process must be real, the video must be attractive, the important content must be pushed forward and the video must be directive for students to do experiments.

\subsection{Sound Media}

Sound media used in science courseware mainly in the explaining of content and the commentary of video. The sound must use stand mandarin standard and the tone must be suitable for the scene. At the same time, we provide the control of sound media, teachers or students can listen or not listen to the sound according their demands.

\section{Conclusion}

One of the new trends in instructional design is to use the abundant media [4]. It is very important to make excellent courseware to enrich the media materials and use them appropriately. The ready-made media materials are not so many and hardly to find. Therefore, in order to enrich the media library, teachers, media creators and courseware creators should collaborate with each other, and develop more Science courseware in the future. 


\section{Acknowledgements}

This work is supported by the 2013 Jiangnan University special project of independent research in humanities and social science, project number: 2013zx16.

\section{References}

[1] (2001) Science Curriculum Standards. Beijing Normsl Univeristy Press, Beijing, 8-10.

[2] Yuan, K.Y. (2001) Science (Grade 7). Eastchina Normsl Univeristy Press, Shanghai, 3-5.

[3] Parrish, P.E. (2009) Aesthetic Principles for Instructional Design. Joint Information Systems Committee (JISC).

[4] Reiser, R.A. and Dempsey, J.V. (2008) Trends and Issues in Instructional Design and Technology. 2nd Edition, Pearson Education, Inc., 312-321. 